\title{
Multicenter prospective validation of the European System for Cardiac Operative Risk Evaluation II in Argentina
}

\author{
Validación prospectiva multicéntrica del EuroSCORE II en Argentina
}

\author{
Raúl A. Borracci ${ }^{1,2 *}$, Miguel Rubio ${ }^{1}$, Julio Baldi Jr. ${ }^{1}$, Julio C. Giorgini ${ }^{2}$, and Claudio C. Higa ${ }^{2}$ \\ ${ }^{1}$ Department of Cardiac Surgery, Hospital de Clínicas, Universidad de Buenos Aires, Argentina; ${ }^{2}$ Department of Cardiology and Cardiovascular \\ Surgery, Deutsches Hospital, Buenos Aires, Argentina
}

\begin{abstract}
Objective: To validate prospectively in multiple centers, the accuracy and clinical utility of the European System for Cardiac Operative Risk Evaluation (EuroSCORE II) to predict the operative mortality of cardiac surgery in Argentina. Methods: Between January 2012 and February 2018, 2000 consecutive adult patients who underwent cardiac surgery in different centers in Argentina were prospectively included. The endpoint was in-hospital all-cause mortality. Discrimination, calibration, precision, and clinical utility of the EuroSCORE II were evaluated in the global cohort and in the different types of surgeries, based on receiver operating characteristics $(R O C)$ curves, Hosmer-Lemeshow goodness-of-fit test, observed/expected mortality ratio, Shannon index, and decision curves analysis. Results: ROC area of the EuroSCORE II was between 0.73 and 0.80 for all types of surgery, being the lowest value for coronary surgery. The observed and expected mortality was $4.3 \%$ and $3.0 \%$, respectively $(p=0.034)$. The decision curve analysis showed a positive net benefit for all thresholds below 0.24 , considering all type of surgeries. Conclusions: The EuroSCORE II showed an adequate performance in terms of discrimination and calibration for all types of surgery, although somewhat inferior for coronary surgery. Although, in general terms, this model underestimated the risk in intermediate-risk groups, its overall performance was acceptable. The EuroSCORE II could be considered an optional updated generic model of operative risk stratification to predict in-hospital mortality after cardiac surgery in our context.
\end{abstract}

Key words: European System for Cardiac Operative Risk Evaluation II. Validation. Risk. Decision curve analysis. Cardiac surgical procedures. Argentina.

\section{Resumen}

Objetivo: Validar, en forma prospectiva y en múltiples centros, la precisión y utilidad clínica del European System for Cardiac Operative Risk Evaluation II (EuroSCORE II) para predecir la mortalidad operatoria de la cirugía cardíaca en centros de Argentina. Método: Entre enero de 2012 y febrero de 2018 se incluyeron en forma prospectiva 2,000 pacientes consecutivos que fueron sometidos a cirugía cardíaca en diferentes centros de Argentina. El punto final fue mortalidad hospitalaria por cualquier causa. La discriminación, calibración, precisión y utilidad clínica del EuroSCORE II se evaluaron en la cohorte

\section{Correspondence:}

${ }^{*}$ Raul A. Borracci

La Pampa, 3030

Date of reception: 06-02-2019

Date of acceptance: 14-03-2019

C.P. 1428, Buenos Aires, Argentina

E-mail: raborracci@gmail.com 2604-7063/@ 2019 Instituto Nacional de Cardiología Ignacio Chávez. Published by Permanyer. This is an open access article under the CC BY-NC-ND license (http://creativecommons.org/licenses/by-nc-nd/4.0/). 
global y en los diferentes tipos de cirugías, basándose en las curvas Receiver Operating Characteristics (ROC), bondad de ajuste de Hosmer-Lemeshow, razón de mortalidad observada/esperada, índice de Shannon y curvas de decisión. Resultados: El área ROC del EuroSCORE Il estuvo entre 0.73 y 0.80 para todo tipo de cirugía, y el valor más bajo fue para la cirugía coronaria. La mortalidad observada y esperada fue 4.3 y $3.0 \%$, respectivamente $(p=0.034)$. El análisis de la curva de decisión demostró un beneficio neto positivo para los umbrales por debajo de 0.24 para todo tipo de cirugía. Conclusiones: El EuroSCORE II tuvo un desempeño adecuado en términos de discriminación y calibración para todos los tipos de cirugía, aunque algo inferior para la cirugía coronaria. Si bien en términos generales subestimó el riesgo en los grupos de riesgo intermedio, el comportamiento global fue aceptable. El EuroSCORE Il podría considerarse una opción de modelo genérico y actualizado de estratificación del riesgo operatorio para predecir la mortalidad hospitalaria de la cirugía cardíaca en nuestro contexto.

Palabras clave: European system for cardiac operative risk evaluation II. Validación. Riesgo. Análisis de curvas de decisión. Procedimientos quirúrgicos cardíacos. Argentina.

\section{Introduction}

Risk stratification models in cardiac surgery fulfill two main functions. On the one hand, they collaborate in therapeutic decision-making according to the pre-operative risk of expected surgery-associated mortality, and on the other hand, they help in the quality control of surgical results in a hospital department ${ }^{1}$. Although there are multiple risk scoring models that can be developed with local data, the use of a worldwide-validated score allows to compare a country's own results with a common international standard.

Effective implementation of an international score requires validating its accuracy in terms of discrimination and calibration in the local sample it is to be applied in. The European System for Cardiac Operative Risk Evaluation (EuroSCORE II) is a scoring system that has been validated several times in other countries and that replaced and adjusted the additive and logistic old versions of the original EuroSCORE ${ }^{2}$. Three meta-analyses showed that, despite the heterogeneity of the included studies, EuroSCORE II shows a good overall performance to predict surgical mortality, although new prospective validations would be necessary for other patient populations ${ }^{3-5}$.

Some inconsistencies in this model have also been pointed out. Since there would be an annual seasonal variation in cardiac surgery-associated mortality, EuroSCORE II data collection exclusively in the northern hemisphere spring summer period might have introduced some bias in the accuracy of the model ${ }^{6}$. Other authors have criticized the quality of EuroSCORE ॥ calibration, which is based only on the Hosmer-Lemeshow $(\mathrm{HL})$ statistic $^{7,8}$, as well as some aspects of design in terms of development and validation of the model $^{9}$. Other studies pointed out that this model might underestimate the risk of mortality in high-risk patients and in those undergoing combined surgery ${ }^{10}$. EuroSCORE II also seems to underestimate endocarditis surgery-associated mortality ${ }^{11}$ and, in some European populations in particular; it does not estimate mortality better than the previous versions ${ }^{12}$. However, many of these criticisms were made shortly after the model was presented, and were softened in recent years as external prospective validations appeared.

The purpose of this study was to prospectively validate, and in multiple centers, EuroSCORE II accuracy, and clinical usefulness to predict surgical mortality associated with cardiac surgery in Argentinian centers.

\section{Methods}

This study included a prospective and consecutive series of 2000 adult patients who underwent cardiac surgery at Hospital de Clínicas of the University of Buenos Aires and its associated hospitals and clinics between January 2012 and February 2018. All types of surgery were included, except for acute aortic dissection, transplantation, and transcatheter aortic valve implantation. Baseline clinical and laboratory data and surgical data were prospectively collected in an ad hoc database, which included the necessary variables to estimate the risk of surgical mortality based on EuroSCORE II. All the definitions proposed by said model of risk stratification were adopted, and the score for each patient was determined with an online interactive calculator (http://www.euroscore.org/calc.html). Additional information on other risk factors, comorbidities, major operative complications, and hospital mortality was added to the computerized database. The endpoint assessed was all-cause hospital mortality. EuroSCORE II discrimination and accuracy were assessed in the global cohort and in the different types of performed surgeries. 


\section{Statistical analysis}

Continuous variables were expressed as the mean \pm standard deviation, and the frequency distribution of the scores was complemented with the interquartile range (IQR). Kolmogorov-Smirnov goodness-of-fit test was used to analyze the normality of distribution. The observed over expected mortality ratio was compared with the Chi-square test or two-tailed Fisher's exact probability test, and represented in a model clinical validation chart, separated by risk groups ${ }^{13}$. Calibration of the model was evaluated with the Hosmer-Lemeshow $(\mathrm{HL})$ goodness-of-fit test, and the area under the receiver operating characteristics (ROC) curve, with its confidence interval $95 \%$, was used to estimate EuroSCORE II discrimination capacity for predicting hospital mortality. EuroSCORE II accuracy was also determined based on the theory of information model, taking into account the risk estimate and the presence or not of the death event (Shannon index) ${ }^{14}$. Finally, the EuroSCORE II net benefit to predict hospital mortality was calculated based on the decision curve analysis ${ }^{15}$. The construction of the decision curve was made with a Microsoft Excel ${ }^{\circledR}$ spreadsheet, and the rest of the statistical analysis was carried out with SPSS Statistics for Windows, Version 17.0 (SPSS, Inc., Chicago, IL, USA).

The study was carried out following the recommendations for research studies in human subjects and current legal regulations. Measures were implemented to protect the confidentiality of all information in accordance with the Argentinian law 25,326 on the protection of personal data. The study protocol was approved by the Review Committee of each participating institution.

\section{Results}

Table 1 summarizes the baseline characteristics of the study population. EuroSCORE II values distribution for the entire population of patients is shown in figure $1 \mathrm{~A}$, where a marked asymmetry leaning to the right is observed, with a median of $1.44 \%$ (IQR: 0.85 $2.72 \%)$. In turn, the ROC curve in figure $1 \mathrm{~B}$ shows an area of 0.80 , with good overall discrimination of the model for the entire cohort, as well as a suitable calibration ( $H L p=0.178$ ). EuroSCORE II performance for each type of surgery in terms of predictive capacity is shown in figure 2 . The position of each bubble in the graph depends on the balance between model calibration and discriminatory power, as assessed with the ROC area. EuroSCORE II is observed to have
Table 1. Baseline characteristics of the population

\begin{tabular}{|c|c|}
\hline Variables & n (\%) \\
\hline $\begin{array}{l}\text { Male gender } \\
\text { Insulin-dependent diabetes } \\
\text { Non-insulin-dependent diabetes } \\
\text { Heart failure } \\
\text { Stroke } \\
\text { Chronic obstructive pulmonary disease } \\
\text { Peripheral artery disease } \\
\text { Dialysis }\end{array}$ & $\begin{array}{c}66.5 \pm 10.7(20-92) \\
\text { años } \\
1429(71.5) \\
52(2.6) \\
386(19.3) \\
95(4.8) \\
70(3.5) \\
112(5.6) \\
46(2.3) \\
16(0.8)\end{array}$ \\
\hline $\begin{array}{l}\text { Unstable angina }{ }^{*, \dagger} \\
\text { Recent myocardial infarction }(<60 \text { days })^{\dagger} \\
\text { Active endocarditis } \\
\text { Previous cardiac surgery } \\
\text { Moderate/severe LV dysfunction } \\
\text { Type of surgery } \\
\text { Coronary } \\
\text { Aortic valve } \\
\text { Mitral valve } \\
\text { Combined } \\
\text { Miscellaneous }{ }^{\ddagger} \\
\text { Urgency/emergency surgery } \\
\text { Coronary surgery without pump }{ }^{\dagger} \\
\text { Use of at least one mammary artery } \\
\text { CPB time (mean } \pm \text { SD) }\end{array}$ & $\begin{array}{c}999(50.0) \\
415(20.7) \\
120(6.0) \\
206(10.3) \\
260(13.0) \\
298(14.9) \\
283(28.3) \\
954(95.5) \\
64.6 \pm 16.0 \mathrm{~min}\end{array}$ \\
\hline $\begin{array}{l}\text { Post-operative } \\
\text { Hospital mortality } \\
\text { Operating room extubation (ultra-fast-track) }\end{array}$ & $\begin{array}{c}85(4.3) \\
1362(68.1)\end{array}$ \\
\hline $\begin{array}{l}\text { Major complications } \\
\text { Reoperation for bleeding } \\
\text { Type } 0 \text { infarction }{ }^{\dagger} \\
\text { Low cardiac output } \\
\text { Prolonged mechanical ventilation }(>48 \mathrm{~h} \text { ) } \\
\text { Stroke } \\
\text { De novo dialysis } \\
\text { Deep sternal infection }\end{array}$ & $\begin{array}{l}31(1.6) \\
18(1.8) \\
51(2.6) \\
34(1.7) \\
16(0.8) \\
21(1.1) \\
24(1.2)\end{array}$ \\
\hline
\end{tabular}

*Defined as the need for intravenous nitrates at the time of surgery. tExclusively calculated for coronary surgery $(n=999)$.

${ }^{\ddagger}$ Miscellaneous includes cardiac neoplasms, ventricular and ascending aorta aneurysm, infarction mechanical, and adult congenital surgery. CPB: cardiopulmonary bypass; SD: standard deviation; LV: left ventricle.

adequate calibration for any type of surgery with all $\mathrm{HL}$ Chi-square values being $<15.0$, and discrimination that ranges from 0.73 to 0.82 .

In figure $3 \mathrm{~A}$, observed versus expected hospital mortality, is compared for all types of surgery. The observed/expected ratio ranged from 1.0 to 2.1 , according to the risk group analyzed. In the model clinical validation graph, EuroSCORE II is observed to have underestimated the risk in patients with intermediate and high risk, but not those at the ends of the distribution. Similarly, Shannon accuracy index decreased from 0.99 to 0.76 as the analysis advanced toward higher risk 


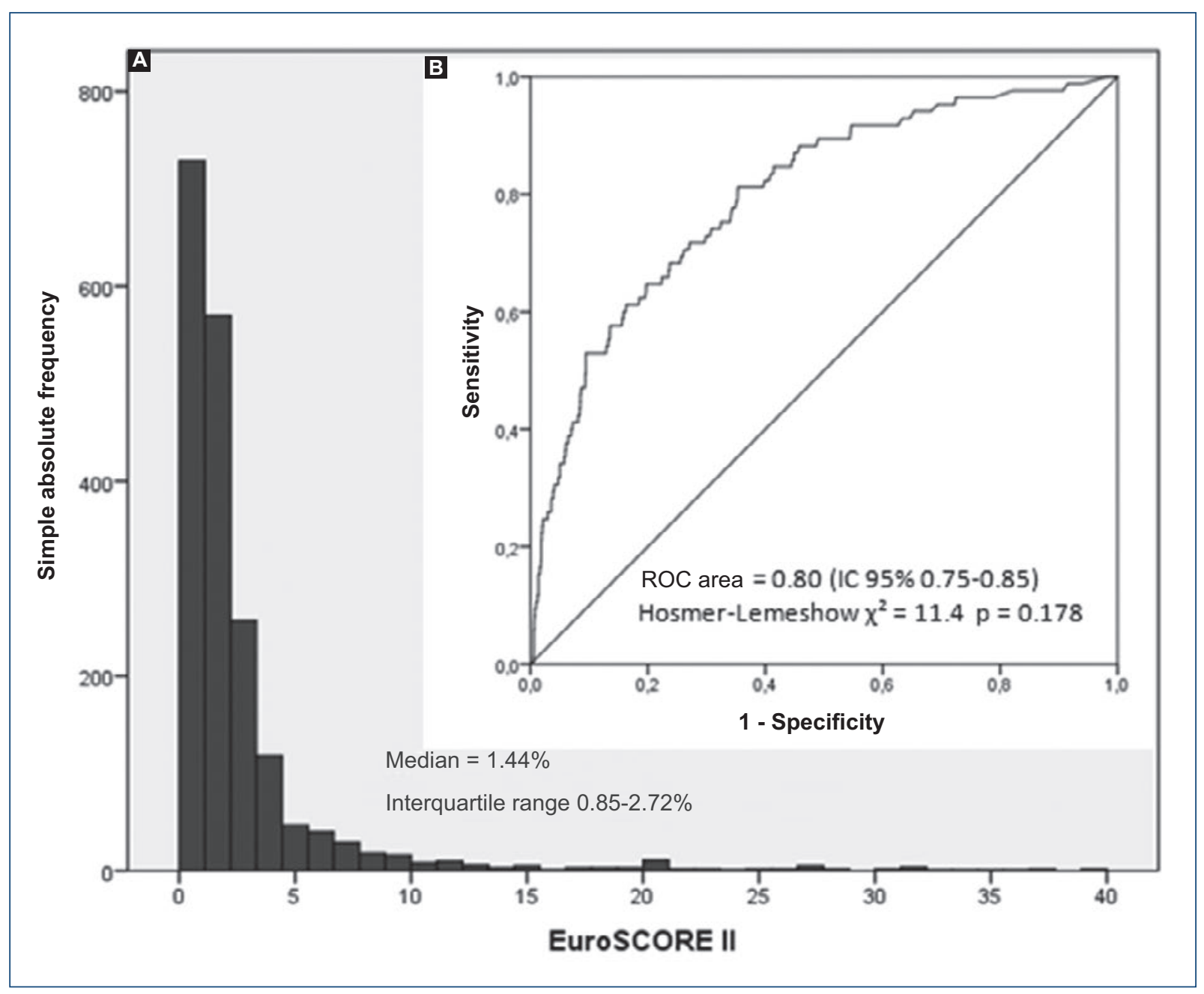

Figure 1. A: Histogram of European System for Cardiac Operative Risk Evaluation (EuroSCORE II) values distribution for the entire patient population. A marked asymmetry on the right is observed. B: Area under the receiver operating characteristics curve of EuroSCORE II performance for the entire patient population.

groups (Fig. 3B), which indicates a reduction in the model accuracy. The observed and expected mortality for the entire sample was 4.3 and $3.0 \%$, respectively, with an observed/expected ratio of $1.4(p=0.034)$. Observed and expected mortality raw data separated by risk groups, as well as their statistical comparison, are summarized in table 2. Observed major complications are presented at the end of table 1.

EuroSCORE II clinical utility to predict hospital mortality was analyzed with the decision curves in figure 4, in terms of net benefit. The results are presented with the probability threshold in the abscissa (the risk of operative mortality beyond which the decision is not to operate the patient), and EuroSCORE II-predicted benefits in the ordinate, for each type of surgery.

\section{Discussion}

The original EuroSCORE started being used in 1999 with both its models, additive, and logistic, to stratify cardiac surgery operative risk, and has been widely validated worldwide ${ }^{16,17}$. As operative care improved and hospital mortality was reduced, EuroSCORE began to overestimate surgical risk ${ }^{18}$. Its successor model is EuroSCORE II, which appeared in 2012, and currently, it follows an external validation process in populations other than those in which the model was developed ${ }^{19}$.

In the current validation study, EuroSCORE II had an adequate overall performance in terms of discrimination and calibration to predict cardiac surgery immediate mortality in this cohort. In particular, the predictive 


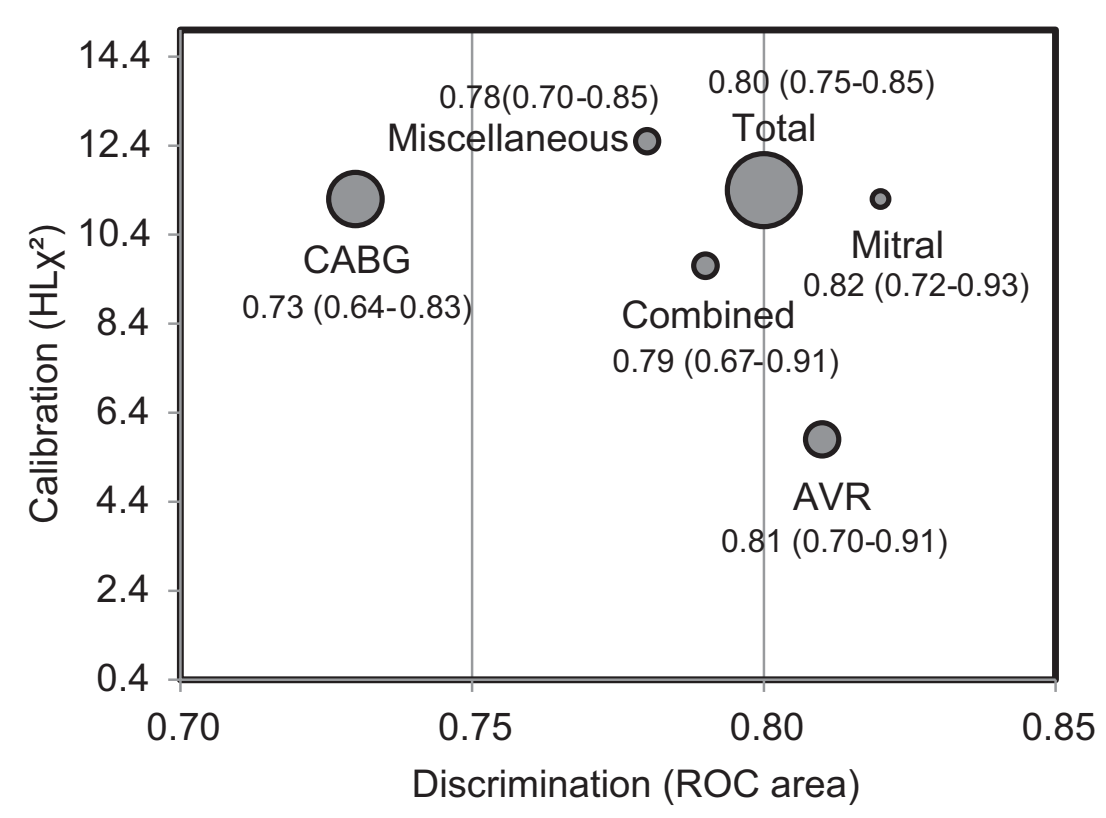

Figure 2. European System for Cardiac Operative Risk Evaluation (EuroSCORE II) performance for each type of surgery in terms of predictive capacity. The position of each bubble in the graph depends on the balance between EuroSCORE II calibration, calculated with Hosmer-Lemeshow Chi-square statistic $\left(H L \chi^{2}\right)$, and discriminatory power as assessed with the area under the receiver operating characteristics (ROC) curve. EuroSCORE II accuracy increases from top to bottom and from left to right. The size of the circles is proportional to each group sample size. The 0.05 threshold for the calibration values is outside the graph by $\mathrm{HL} \chi^{2}=15.0$. The values in brackets correspond to the ROC area confidence intervals.

CABG: coronary artery bypass grafting; AVR: aortic valve replacement.

capacity was better in patients undergoing valvular or combined surgery, than in myocardial revascularization surgery alone. Clinical validation of the model, based on the observed/expected mortality ratio and the Shannon index, showed that the system behaved better in groups of patients with lower and higher risk, while it underestimated the risk in intermediate groups.

In a previous publication, EuroSCORE II was validated in a cohort of 503 patients ${ }^{20}$, whereas on this occasion, the sample was broadened to 2000 patients and more health centers were included in the study. Comparatively, the current series corroborated a better performance of the score in patients undergoing non-coronary heart surgery. Since its introduction in clinical practice, EuroSCORE II was assessed in more than 50 studies with different results. The meta-analysis by Guida et al. ${ }^{3}$, which included 22 studies, showed overall discrimination of 0.79 , similar to that in our study. The most recent publications, not included yet in a systematic review, include some of the following: Iran ${ }^{21}$, China ${ }^{22,23}$, Greece ${ }^{24}$, Spain ${ }^{25,26}$, India ${ }^{27}$, US $^{28,29}$, and the Netherlands ${ }^{30}$, with $\mathrm{ROC}$ areas ranging from 0.67 to 0.87 .

The comparison of observed mortality in the local setting with the same international results is important to establish patterns of quality and continuous improvement. For example, overall mortality for all types of surgery in our study was $4.3 \%$, while in comparable populations from the United Kingdom and the Netherlands who also used EuroSCORE II, the same mortality rate was $3.0 \%$ and $2.7 \%$, respectively ${ }^{31,32}$.

In particular, in our study, EuroSCORE II showed a good performance to predict the risk of aortic valve replacement. Although it would be expected that this model could also be used to assess percutaneous valve implantation, a recent meta-analysis showed that EuroSCORE II reached a discriminative power of only 0.62 with the endovascular method ${ }^{33}$. In the meta-analysis by Biancari et al. ${ }^{4}$, which exclusively assessed EuroSCORE II performance in aortic valve replacement, the ROC area found was 0.73. On the other hand, Carosella et al..$^{34}$ found that a local score, ArgenSCORE, showed a better discriminative power (ROC 

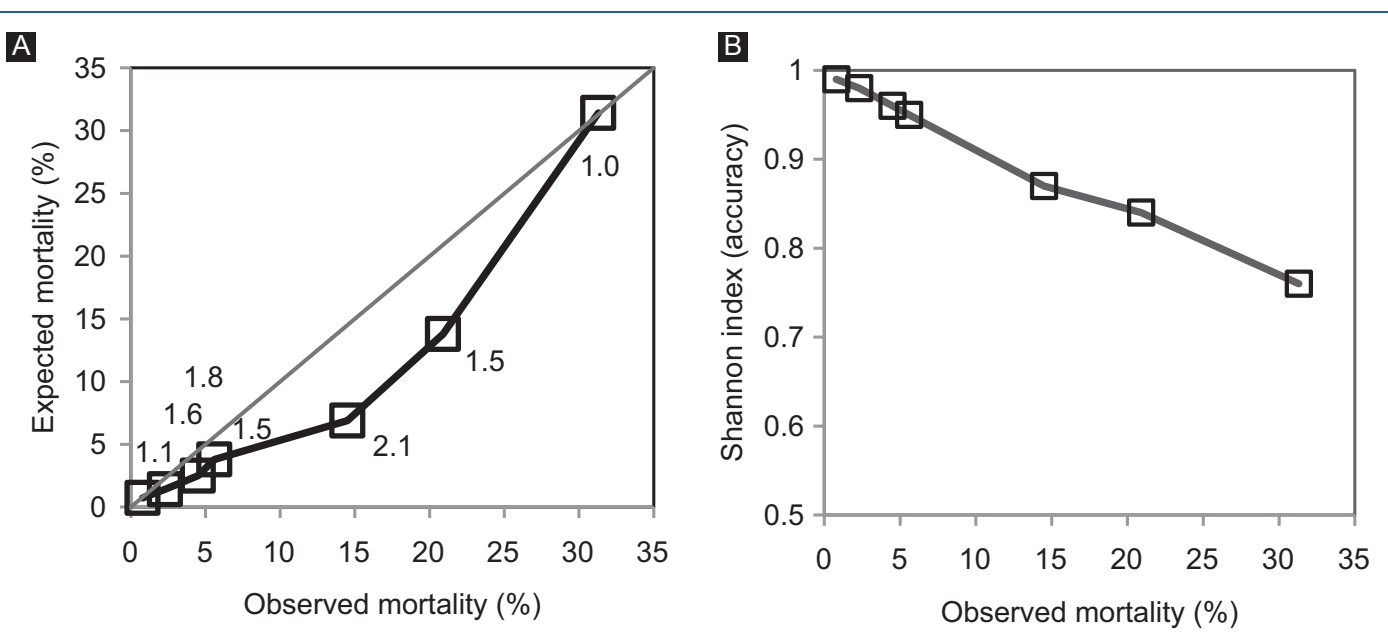

Figure 3. Clinical validation graph of the model separated by risk groups. A: Observed versus expected mortality according to the European System for Cardiac Operative Risk Evaluation II for all types of surgery. The values on each point correspond to the observed/expected ratio. B: Prediction accuracy based on the Shannon index. The squares represent patients grouped by the same risk. Since risk distribution was skewed to the right, dividing the series into groups of different sizes and not by fractiles was preferred.

Table 2. Observed and expected mortality separated by risk groups

\begin{tabular}{|l|c|c|c|c|c|c|}
\hline Risk groups & $\mathbf{N}$ & Deaths & Observed mortality (0) & Expected mortality (E) & $\mathbf{0 : E}$ & $\mathbf{p}$ \\
\hline $0-1$ & 666 & 5 & $0.8 \%$ & $0.7 \%$ & 1.1 & 1.000 \\
\hline $1-2$ & 628 & 14 & $2.2 \%$ & $1.4 \%$ & 1.6 & 0.293 \\
\hline $2-3$ & 292 & 13 & $4.5 \%$ & $2.5 \%$ & 1.8 & 0.172 \\
\hline $3-5$ & 198 & 11 & $5.6 \%$ & $3.8 \%$ & 1.5 & 0.481 \\
\hline $5-10$ & 124 & 18 & $14.5 \%$ & $6.9 \%$ & 2.1 & 0.066 \\
\hline $10-20$ & 44 & 9 & $20.5 \%$ & $13.8 \%$ & 1.5 & 0.395 \\
\hline$>20$ & 48 & 15 & $31.3 \%$ & $31.4 \%$ & 1.0 & 1.000 \\
\hline Total & 2000 & 85 & $4.3 \%$ & $3.0 \%$ & 1.4 & 0.034 \\
\hline
\end{tabular}

area $=0.82)$ than EuroSCORE II (ROC area $=0.76)$, when they compared surgical aortic valve replacement results. In a study published in 2011, the ArgenSCORE ROC area was $0.80(0.75-0.85)$ for all types of surgery, similar to that found in our current study based on EurOSCORE II and carried out almost a decade later ${ }^{35}$. Anyway, since it is an international score, EuroSCORE II would allow the comparison of local results with global quality standards and thus would avoid comparison bias with scores developed exclusively for local use.

Surgical mortality variation between centers and surgeons is usually broad, and it should be taken into account when using any risk stratification model; therefore, making an adjustment in EuroSCORE II-predicted risk with the so-called risk-adjusted mortality ratio (RAMR) has been suggested ${ }^{36,37}$. RAMR is an individual index for each center or surgeon, which corresponds to the ratio between observed and expected mortality in the set of patients. In our study, this ratio was 1.4; therefore, to obtain the real expected risk, this ratio is multiplied by EuroSCORE II-predicted mortality. For example, if the expected mortality risk of a patient is $5 \%$, the actual corrected risk will be $7 \%$.

It is increasingly common to include an analysis of decision curves in the assessment of the clinical usefulness of a model. Calibration and discrimination are important aspects of a prediction model, but fail to assess the capability to make better decisions with or without the use 


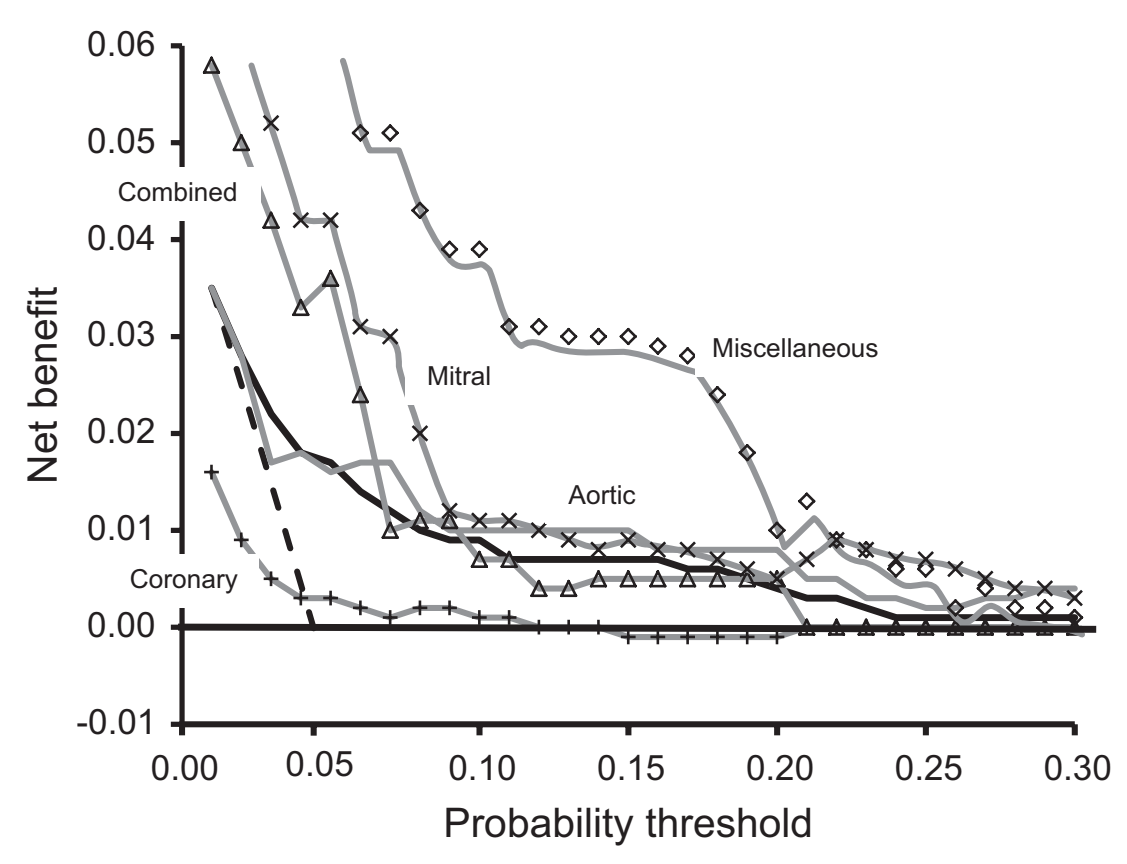

Figure 4. European System for Cardiac Operative Risk Evaluation (EuroSCORE II) decision curves for predicting hospital mortality applied to 2000 patients undergoing cardiac surgery. The solid horizontal line that appears beyond zero assumes that no patient is treated (considers that all will die after surgery), and the net benefit is therefore zero. The dotted line assumes that all patients are treated (considers that all will survive), while the gray lines assume that patients are treated only if the predictions exceed a certain threshold, with the expected risk based on EuroSCORE II. Each gray line with marks represents a different type of surgery. The solid black line summarizes the net benefit of all surgeries together. The graph represents the expected net benefit per patient for the different thresholds, in comparison with not treating any patient. The dotted gray lines that would assume treatment for all patients for each type of surgery were not included to give greater clarity to the graph.

of the model. The sum of sensitivity and specificity based on Youden's index is an average indicator of the usefulness of a model, but it ignores the relative weight of true and false positives. Recently, the calculation of the net profit based on different decision thresholds has been proposed to classify the patients who would benefit or not with the treatment. This analysis compares the risks and benefits of a decision, calculating the weighted sum of true positive cases minus the false positives. As shown in figure 4 , with a threshold of 0.24 , the benefit of treating a patient is practically zero, according to the expected risk calculated with EuroSCORE II for all kinds of surgery.

When observing EuroSCORE II underestimation in our intermediate-risk patients, three possible interpretations are posed: inadequate behavior of the model, poor performance of surgeons in that risk stratum, or both simultaneously. When data of the current study are compared with hospital results for aortic valve surgery, alone or combined, in patients with intermediate-risk (EuroSCORE II or Society of Thoracic Surgeons-STS between $4 \%$ and $7 \%$ ) carried out in two other reference centers of the country, a lower overall mortality was observed with regard to results reported by us in previous a study ${ }^{38-40}$. This observation would support at least the second interpretation of EuroSCORE II validity in patients with intermediate-risk in our sample.

One of the main strengths of our study is that the data were prospectively collected since EuroSCORE II implementation and that its clinical usefulness was analyzed with a decision curve model. On the other hand, a possible limitation of our cohort is that almost $90 \%$ of patients had a risk lower than or equal to $5 \%$, which is a fact that might bias the overall performance of the score, since its behavior seems to be better in patients with lower risk. In addition, the sample size for some categories or risk groups might be too small to demonstrate statistical differences with regard to the mortality expected in these categories. Another limitation is that although our study population is a large cohort of patients from several centers, the sample does not represent the entire population undergoing cardiac surgery in Argentina. Regarding EuroSCORE II good performance in low-risk cases, this might be due to the fact that these patients with less comorbidities would require less post-operative 
care technological support, which is often a limitation in developing countries. Conversely, in patients at higher risk, the surgical performance itself would be proportionately less important than post-operative care. With regard to EuroSCORE II good performance in patients at very high risk, this observation could be biased by the small size of the sample in this stratum $(n=15)$.

\section{Conclusions}

EuroSCORE II had an adequate performance in terms of discrimination and calibration for all types of surgery, although somewhat lower for coronary surgery. Although, in general terms, it underestimated the risk in intermediate-risk groups, overall behavior was acceptable. The decision curve analysis for all types of surgery showed a positive net benefit for all thresholds below of 0.24 . EuroSCORE II could be considered a generic and updated operative risk stratification model option to predict cardiac surgery hospital mortality in our context.

\section{Funding}

The present investigation has not received specific aid from public or commercial sector agencies or non-profit entities.

\section{Conflicts of interest}

The authors declare that they have no conflicts of interest regarding this article.

\section{Ethical disclosures}

Protection of people and animals. The authors declare that no experiments were performed on humans or animals for this study.

Confidentiality data. The authors declare that they have followed the protocols of their work center on the publication of patient data.

Right to privacy and informed consent. The authors declare that no patient data appear in this article.

\section{References}

1. Borracci RA, Arribalzaga EB. Fuzzy logic-based model to stratify cardiac surgery risk. Rev Argent Cardiol. 2015;83:304-11.

2. Nashef SA, Roques F, Sharples LD, Nilsson J, Smith C, Goldstone AR, et al. EuroSCORE II. Eur J Cardiothorac Surg. 2012; 41:734-44.

3. Guida P, Mastro F, Scrascia G, Whitlock R, Paparella D. Performance of the European System for Cardiac Operative Risk Evaluation II: a meta-analysis of 22 studies involving 145,592 cardiac surgery procedures. J Thorac Cardiovasc Surg. 2014;148:3049-57.
4. Biancari F, Juvonen T, Onorati F, Faggian G, Heikkinen J, Airaksinen J, et al. Meta-analysis on the performance of the EuroSCORE II and the Society of Thoracic Surgeons Scores in patients undergoing aortic valve replacement. J Cardiothorac Vasc Anesth. 2014;28:1533-9.

5. Sullivan PG, Wallach JD, Ioannidis JP. Meta-Analysis Comparing Established Risk Prediction Models (EuroSCORE II, STS Score, and ACEF Score) for Perioperative Mortality During Cardiac Surgery. Am J Cardiol. 2016;118:1574-82.

6. Poullis M, Fabri B, Pullan M, Chalmers J. Sampling time error in EuroSCORE II. Interact Cardiovasc Thorac Surg. 2012;14:640-1.

7. Collins GS, Altman DG. Calibration of EuroSCORE II. Eur J Cardiothorac Surg. 2013;43:654.

8. Hickey GL, Bridgewater B. How well calibrated is EuroSCORE ॥? Eur J Cardiothorac Surg. 2013;43:208.

9. Collins GS, Altman DG. Design flaws in EuroSCORE II. Eur J Cardiothorac Surg. 2013; 43:871.

10. Spiliopoulos K, Bagiatis V, Deutsch O, Kemkes BM, Antonopoulos N, Karangelis D, et al. Performance of EuroSCORE II compared to EuroSCORE I in predicting operative and mid-term mortality of patients from a single center after combined coronary artery bypass grafting and aortic valve replacement. Gen Thorac Cardiovasc Surg. 2014;62:103-11.

11. Patrat-Delon S, Rouxel A, Gacouin A, Revest M, Flécher E, Fouquet O, et al. EuroSCORE II underestimates mortality after cardiac surgery for infective endocarditis. Eur J Cardiothorac Surg. 2016;49:944-51.

12. Janikowski K, Morawiec R, Jegier B, Jaszewski R, Lelonek M. EuroSCORE II does not show better accuracy nor predictive power in comparison to original EuroSCORE: a single-centre study. Kardiol Pol. 2016;74:469-75

13. Steyerberg EW, Vergouwe $Y$. Towards better clinical prediction models: seven steps for development and an ABCD for validation. Eur Heart J. 2014;35:1925-31.

14. Borracci RA, Tajer CD. Aplicación de la teoría de la información a la investigación clínica. Rev Argent Cardiol. 2006;74:483-6.

15. Vickers AJ, Elkin EB. Decision curve analysis: a novel method for evaluating prediction models. Med Decis Mak. 2006;26:565-74.

16. Nashef SA, Roques F, Michel P. European system for cardiac operative risk evaluation (EuroSCORE). Eur J Cardiothorac Surg. 1999;16:9-13.

17. Borracci RA, Rubio M, Baldi J (Jr), Arribalzaga EB, Poveda Camargo RL. Cardiac surgery stratified by EuroSCORE. Long-term survival. Medicina (Buenos Aires). 2013;73:438-42.

18. Parolari A, Pesce LL, Trezzi M, Loardi C, Kassem S, Brambillasca C et al. Performance of EuroSCORE in CABG and off-pump coronary artery bypass grafting: single institution experience and meta-analysis. Eur Heart J. 2009:30:297-304.

19. Collins GS, Altman DG. Design flaws in EuroSCORE II. Eur J Cardiothorac Surg. 2013;43:871

20. Borracci RA, Rubio M, Celano L, Ingino CA, Allende NG, Ahuad Guerrero RA. Prospective validation of EuroSCORE II in patients undergoing cardiac surgery in Argentinean centres. Interact Cardiovasc Thorac Surg. 2014;18:539-43

21. Atashi A, Amini S, Tashnizi MA, Moeinipour AA, Aazami MH, Tohidnezhad $F$, et al. External Validation of European System for Cardiac Operative Risk Evaluation II (EuroSCORE II) for Risk Prioritization in an Iranian Population. Braz J Cardiovasc Surg. 2018;33:40-6.

22. Shen L, Chen X, Gu J, Xue S. Validation of EuroSCORE II in Chinese Patients Undergoing Coronary Artery Bypass Surgery. Heart Surg Forum. 2018;21:E036-9.

23. Ma X, Wang Y, Shan L, Cang Z, Gu C, Qu N, et al. Validation of SinoSCORE for isolated CABG operation in East China. Sci Rep. 2017;7:16806.

24. Stavridis G, Panaretos D, Kadda O, Panagiotakos DB. Validation of the EuroSCORE II in a Greek Cardiac Surgical Population: A Prospective Study. Open Cardiovasc Med J. 2017;11: 94-101.

25. Mateos-Pañero B, Sánchez-Casado $M$, Castaño-Moreira $B$, Paredes-Astillero I, López-Almodóvar LF, Bustos-Molina F. Assessment of Euroscore and SAPS III as hospital mortality predicted in cardiac surgery. Rev Esp Anestesiol Reanim. 2017;64:273-81.

26. Garcia-Valentin A, Mestres CA, Bernabeu E, Bahamonde JA, Martín I, Rueda C, et al. Validation and quality measurements for EuroSCORE and EuroSCORE II in the Spanish cardiac surgical population: a prospective, multicentre study. Eur J Cardiothorac Surg. 2016:49:399-405.

27. Pillai BS, Baloria KA, Selot N. Validation of the European System for Cardiac Operative Risk Evaluation-II model in an urban Indian population and comparison with three other risk scoring systems. Ann Card Anaesth. $2015 ; 18: 335-42$.

28. Osnabrugge RL, Speir AM, Head SJ, Fonner CE, Fonner E, Kappetein $\mathrm{AP}$, et al. Performance of EuroSCORE II in a large US database: implications for transcatheter aortic valve implantation. Eur $\mathrm{J}$ Cardiothorac Surg. 2014;46:400-8; discussion 408.

29. Hernández-Vaquero D, Díaz R, Meana B, Morís C. External validation of the EuroSCORE II risk stratification model in the USA. Eur J Cardiothorac Surg. 2015;48:177. 
30. Hogervorst EK, Rosseel PMJ, van de Watering LMG, Brand A, Bentala M, van der Meer BJM, et al. Prospective validation of the EuroSCORE II risk model in a single Dutch cardiac surgery centre. Neth Heart J. 2018:26(11):540-51.

31. Bridgewater B, Hickey GL, Cooper G, Deanfield J, Roxburgh J; Society for Cardiothoracic Surgery in Great Britain and Ireland; National Institute for Clinical Outcomes Research, UCL. Publishing cardiac surgery mortality rates: lessons for other specialties. BMJ. 2013:346:f1139.

32. Siregar S, Groenwold RH, Versteegh MI, Takkenberg JJ, Bots ML, van der Graaf $Y$, et al. Data Resource Profile: adult cardiac surgery database of the Netherlands Association for Cardio-Thoracic Surgery. Int $J$ Epidemiol. 2013;42:142-9.

33. Wang TKM, Wang MTM, Gamble GD, Webster M, Ruygrok PN. Performance of contemporary surgical risk scores for transcatheter aortic valve implantation: A meta-analysis. Int J Cardiol. 2017:236:350-5.

34. Carosella VC, Mastantuono C, Golovonevsky V, Cohen V, Grancelli H, Rodríguez W, et al. Prospective and Multicentric Validation of the ArgenSCORE in Aortic Valve Replacement Surgery. Comparison with the EuroSCORE I and the EuroSCORE II. Rev Argent Cardiol. 2014;82:6-12.
35. Carosella VC, Grancelli H, Rodríguez W, Sellanes M, Cáceres M, Cohen Arazi $\mathrm{H}$, et al. External and Temporal Validation 10 Years after the Development of the First Latin-American Risk Stratification Score for Cardiac Surgery (ArgenSCORE). Rev Argent Cardiol. 2011;79:500-7.

36. García-Villarreal OA. EuroSCORE II. Cómo se usa en la práctica diaria. Rev Mex Cardiol. 2014;25:50-51.

37. Garcia-Villarreal OA: Risk-adjusted mortality ratio for EuroSCORE II in everyday clinical practice. Interact Cardiovasc Thorac Surg. 2014;18:450.

38. Navia D, Piccinini F, Vranvic M, Camporotondo M, Espinoza J, Simonetto B, et al. Early and Long-term Outcomes of Aortic Valve Replacement Surgery in Low- and Intermediate-risk Patients. Rev Argent Cardiol. 2018;86:190-5.

39. Fortunato GA, Marenquino RG, Cirio S, Rossi E, Domenech A, Kotowicz V. Aortic Valve Replacement in Intermediate Risk Patients: Surgical Outcomes. Rev Argent Cardiol. 2018:86:114-7.

40. Borracci RA, Rubio M, Baldi J Jr, Ahuad Guerrero RA, Mauro V, Ingino CA. In-hospital Outcomes of Surgical Aortic Valve Replacement: The Benchmark for Transcatheter Valve Implant. Rev Argent Cardiol. 2018;86:196-9. 